\title{
Ecology and neuroethology of bat echolocation: a tribute to Gerhard Neuweiler
}

\author{
Björn M. Siemers • Lutz Wiegrebe • \\ Benedikt Grothe
}

Received: 10 February 2011/Revised: 10 February 2011/Accepted: 12 February 2011/Published online: 8 April 2011 (c) Springer-Verlag 2011

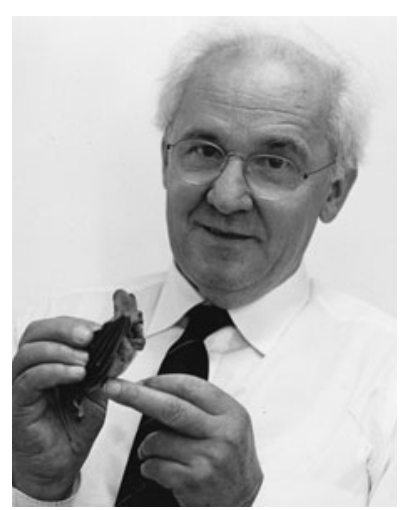

Gerhard Neuweiler (1935-2008) holding a Megaderma lyra at the University of Munich (private photo)

Gerhard Neuweiler was born on 18 May 1935 in a small village in the black forest in south-western Germany. From 1955 to 1962 , he studied biology, chemistry, biochemistry and physics at the universities of Tübingen and Munich. For his doctoral dissertation, he investigated the anatomy and physiology of the visual system, and especially the eye, in the Indian flying fox (Pteropus giganteus). He also developed an interest in the behavior of these large non-

This special issue of the Journal of Comparative Physiology is dedicated to the memory of the late Professor Dr. Gerhard Neuweiler and his legacy in bat echolocation research. Professor Neuweiler died on 15 August 2008 in Munich.

\section{B. M. Siemers ( $\square)$}

Max Planck Institute for Ornithology,

Sensory Ecology Group, Seewiesen, Germany

e-mail: siemers@orn.mpg.de

L. Wiegrebe · B. Grothe

Division of Neurobiology, Department Biology II,

Ludwig-Maximilians-Universität Munich, Munich, Germany echolocating bats. This work was supervised by Franz Möhres, head of the Tübingen animal physiology department at the time. In 1962, Gerhard Neuweiler was awarded the doctoral degree (Dr. rer. nat.) with distinction (summa cum laude).

After his PhD, Gerhard Neuweiler moved to India for 2 years to study behavior and social interactions of flying foxes in the wild. For this time, he was a fellow of the government of India and of the German Academic Exchange Service. Gerhard Neuweiler used these Indian years to get deeply familiar with the fauna and flora, but also the art, the religion and the people of his guest country. Throughout his scientific career, he kept research contacts with India and Sri Lanka and returned many times. In 1986, Neuweiler was awarded an honorary professorship at the Department of Animal Behaviour and Neurobiology at Madurai University. Later, he was nominated Honorary Fellow of the Indian Academy of Sciences Bangalore and Distinguished Fellow of Jawaharlal Nehru Centre for Advanced Scientific Research in Bangalore. It was also in India that Neuweiler and Indian colleagues performed an early comparative study on bat audition, published in the present journal (Neuweiler et al. 1984). This might have marked the onset of Neuweiler's interest in the adaptation of bat echolocation systems to ecology; a topic on which he later published several influential review papers (Neuweiler 1989, 1990). And it was again in India and Sri Lanka where he gained important insights into echolocation behavior of free-ranging bats in the field (Habersetzer et al. 1984; Neuweiler et al. 1987).

But first back to Germany. Gerhard Neuweiler returned from Madurai to Tübingen in 1964. He continued at the Department of Animal Physiology, first as an assistant professor ("Wissenschaftlicher Assistent", 1964-1970) and after his habilitation, in 1970, as an associate professor 
("Oberassistent", 1970-1971). At this time, his interest turned from vision and social behavior of flying foxes to bat echolocation. His initial work in this field is documented by important papers on the echolocation behavior and spatial memory of Megaderma lyra (Neuweiler and Möhres 1967) and on the neurophysiology of echolocation in Rhinolophus ferrumequinum (Neuweiler 1970, 1971; Schuller et al. 1971).

In the course of the student protests of the late 1960s, Gerhard Neuweiler got involved with university politics and debates. Together with others, he established a research group that aimed to replace hierarchies by collegiality. This involved a lot of discussions, meetings and an alleged "constitution" of the working group. The experiment turned out very successful, both in breaking up old, overly hierarchical university traditions as well as scientifically. As a result of this double success of Gerhard Neuweiler and the entire group, he soon became the Chair for Animal Physiology at the University of Frankfurt (1972-1980). Hans-Ulrich Schnitzler who was also part of the group in Tübingen moved to Frankfurt as well as an associate professor. The research of this team had been funded by a large grant by the Volkswagen Foundation already in Tübingen and later in Frankfurt by the German Research Foundation (DFG). Renowned scientists came for prolonged visits and research collaborations; they are, Nobuo Suga, Alan Grinnell, Jim Simmons, Bill Henson and George Pollak. Gerhard Neuweiler and his team and colleagues worked at the forefront of echolocation research. A key topic was the acoustic fovea in horseshoe bats and the neural architecture of the echolocation system in bats that use constant frequency (CF) signals. In this special issue, the review by Schnitzler and Denzinger (2011) gives a detailed account on how this field of research developed from the early days to date. A name that is intimately linked to the discovery of the acoustic fovea is Gerd Schuller, as are those of George Pollak, Volkmar Bruns and Marianne Vater. Schuller was a member of the Neuweiler group since Tübingen times. He had moved to Munich as an associate professor when Gerhard Neuweiler was appointed to the highly renowned chair of Zoology at the University of Munich in 1980. Here, Neuweiler was the successor of Hansjochem Autrum, Karl von Frisch, and several other famous German zoologists. Neuweiler continued in this prestigious position until his retirement in 2003 .

A few years after taking over the Munich chair, Gerhard Neuweiler became a key player in German science politics. He was a member of the senate of the German Research Foundation (1991-1997) and member (1988-1994) and head (1993/1994) of the Science Advisory Board for the German government. In the late 1990s, he also advised the Minister for Higher Education with respect to restructuring the German academic career system. Additionally, Neuweiler was a member of the advisory boards of many research institutions. From 2001 to 2002 he was the president of the German Zoological Society. In his work and vision for science politics, Neuweiler consequently advocated that scientific performance should outweigh privileges that come merely with tradition and position. He was convinced that young scientists should be considered seriously and given a chance, including a good research funding, early on. As a zoologist, he promoted a modern approach with state-of-the-art methods, but an integrative concept that would aim to understand genes, ion channels, cells and brains in the context of the whole organism, of ecology and evolution.

Gerhard Neuweiler's scientific merits and his political achievements alike are mirrored in a long list of honors and awards. Just to name a few, he was a member of the Bavarian Academy of Sciences, Munich, the Academia Europaea, Cambridge UK, the German Science Academy "Leopoldina", Halle, the Academy of Sciences NordrheinWestfalen, Düsseldorf and the Austrian Academy of Sciences, Vienna. He received the Karl Ritter von Frisch Prize of the German Zoological Society and the Felix-Santschi Prize of the University of Zürich.

Neuweiler wrote an epochal text book on bat biology (Neuweiler 2000) and, together with Gerhard Heldmaier, a two volume textbook on comparative animal physiology (Heldmaier and Neuweiler 2003). Together with his friend, the Hungarian composer György Ligeti, he wrote a stimulating book on motoric intelligence-between music and science (Ligeti and Neuweiler 2007). Gerhard Neuweiler's last book appeared shortly after his death. It is his scientific and philosophical legacy, as it illuminates the role and position of our own kind, Homo sapiens, in the evolution of life and of biological complexity on earth (Neuweiler 2008).

Gerhard Neuweiler was an editor of the Journal of Comparative Physiology A from 1982 to 2003. We are glad that we can honor his memory with a special issue on bat echolocation in this very journal. We are grateful to the journal's editor-in-chief, Professor Friedrich Barth, for the invitation and strong support for this project. Gerhard Neuweiler and Friedrich Barth were colleagues at the University of Frankfurt for many years, a time which they both have always considered particularly productive and rewarding (see also Barth 2008). In emails and personal conversations, many colleagues have expressed their admiration for Gerhard Neuweiler and how important he was in inspiring the careers and thoughts of many of us. We received contributions from scientists of four generations of echolocation research and with expertise in many different aspects of bat echolocation. The papers come from colleagues in South Africa, Canada, the USA, Israel, the 
United Kingdom, Denmark and Germany. Thanks to the concerted effort of all authors and referees the special issue gives a colorful and up-to-date account of our research field that will likely mirror, and partly answer, questions that have intrigued Gerhard Neuweiler throughout his scientific life.

We have structured the special issue into three thematic sections: (1) behavioral ecology of bat echolocation, (2) echolocation performance, and (3) the neurobiology and neuroethology of bat echolocation.

The first section on behavioral ecology of bat echolocation is started off by three studies that documented echolocation behavior under field conditions or in seminatural settings and used behavioral experiments to pinpoint the sensory basis of prey perception. Schmidt et al. (2011) investigated echolocation of Megaderma lyra in the field. This species had been intensively used for lab studies on echolocation and psychophysics, including early studies by Gerhard Neuweiler, but up to now echolocation data from the wild is not available. Ratcliffe et al. (2011) highlighted call intensity as an important, yet hitherto little attended parameter in the degrees of freedom bats have for adapting call design to the current echolocation task they face. Holderied et al. (2011) showed how foraging Otonycteris hemprichii key in on the rustling sounds of scorpions. Odendaal and Jacobs (2011) investigated the influence of skull morphology on echolocation call frequency in Rhinolophus capensis. Jones and Siemers (2011) reviewed the potential of bat echolocation calls for eavesdropping and communication between individual bats and across species boundaries. Monroy et al. (2011) documented the ontogeny of communication and echolocation calls in Eptesicus fuscus. Necknig and Zahn (2011) presented evidence that Pipistrellus pipistrellus may alter call frequency to avoid jamming of their sonar even in response to the presence of heterospecific bats.

The section on echolocation performance starts with a review by Yovel et al. (2011a) on the emerging field of how bats classify echoes that return from complex structures such as plants or other types of background. Falk et al. (2011) studied how free-flying big brown bats adapt flight, call pattern and sonar gaze in a texture discrimination task. Melcón et al. (2011) showed that in situations where ambiguities in call-echo assignment are likely to arise, mouse-eared bats frequently change the pulse interval, likely to resolve ambiguity. In another review paper, Yovel et al. (2011b) compared echolocation performance and signal design in tongue-clicking fruit bats and in the laryngeal echolocating big brown bat. Finally, Schmidtke and Esser (2011) showed that male bats differ from female bats in how they orientate by using echo acoustic landmarks.
The third and largest section contains a series of papers on the neurobiology and neuroethology of bat echolocation. For the first paper of this section, Schnitzler and Denzinger (2011), as already mentioned above, reviewed the discovery and investigation of the auditory fovea and of Doppler shift compensation. Borina et al. (2011) found a population of auditory midbrain neurons that are sensitive to interaural time differences of the echo envelope and suggest that, in addition to interaural intensity differences, interaural time differences are used for object location by echolocating bats. Sayegh et al. (2011) reviewed duration tuning in the auditory midbrain of both echolocating and non-echolocating vertebrates. Likewise, Simmons and Simmons (2011) took a comparative approach to echolocating bats and non-echolocators, such as frogs, in pursuit of a common central timing mechanism to extract periodicity pitch. And also Feng (2011) linked data from the frog auditory system to delay-tuning and neural mechanisms of target ranging in bats that use frequency-modulated (FM) calls. Hagemann et al. (2011) then studied cortical echo delay-tuning in a phyllostomid bat that uses multiharmonic FM signals and in the CF-echolocating mustached bat. Fuzessery et al. (2011) presented an overview on the mechanisms that shape selectivity for FM sweep rate and direction in the inferior colliculus and auditory cortex of the pallid bat. In the concluding chapter, Pollak (2011) summarized and reviewed work largely from his own lab on the mechanisms that enable the neurons in the inferior colliculus to respond selectively to a variety of communication and echolocation signals, a long-term research interest of the author that was stimulated by Gerhard Neuweiler.

Gerhard Neuweiler's own work as well as his inspiration, encouragement, and mentorship will continue to influence our field. We pay him tribute with this special issue that is dedicated to his memory.

February 2011, Seewiesen and Munich

Björn M. Siemers, Lutz Wiegrebe and Benedikt Grothe.

\section{References}

Barth FG (2008) Gerhard Neuweiler. Yearbook Austrian Acad Sci 158:565-571

Borina F, Firzlaff U, Wiegrebe L (2011) Neural coding of echoenvelope disparities in echolocating bats. J Comp Physiol A 197 (in this issue). doi:10.1007/s00359-010-0571-z

Falk B, Williams T, Aytekin M, Moss CF (2011) Adaptive behavior for texture discrimination by the free-flying big brown bat, Eptesicus fuscus. J Comp Physiol A 197 (in this issue). doi: 10.1007/s00359-010-0621-6

Feng AS (2011) Neural mechanisms of target ranging in FM bats: physiological evidence from bats and frogs. J Comp Physiol A 197 (in this issue). doi:10.1007/s00359-010-0533-5 
Fuzessery ZM, Razak KA, Williams AJ (2011) Multiple mechanisms shape selectivity for FM sweep rate and direction in the pallid bat inferior colliculus and auditory cortex. J Comp Physiol A 197 (in this issue). doi:10.1007/s00359-010-0554-0

Habersetzer J, Schuller G, Neuweiler G (1984) Foraging behavior and Doppler-shift compensation in echolocating hipposiderid bats, Hipposideros bicolor and Hipposideros speoris. J Comp Physiol A $155: 559-567$

Hagemann C, Vater M, Kössl M (2011) Comparison of properties of cortical echo delay-tuning in the short-tailed fruit bat and the mustached bat. J Comp Physiol A 197 (in this issue). doi: 10.1007/s00359-010-0530-8

Heldmaier G, Neuweiler G (2003) Vergleichende Tierphysiologie. Springer, Berlin

Holderied MW, Korine C, Moritz T (2011) Hemprich's long-eared bat (Otonycteris hemprichii) as a predator of scorpions: whispering echolocation, passive gleaning and prey selection. J Comp Physiol A 197 (in this issue). doi: 10.1007/s00359-0100608-3

Jones G, Siemers BM (2011) The communicative potential of bat echolocation pulses. J Comp Physiol A 197 (in this issue). doi: 10.1007/s00359-010-0565-x

Ligeti G, Neuweiler G (2007) Motorische Intelligenz: Zwischen Musik und Naturwissenschaft. Wagenbach, Berlin

Melcón ML, Yovel Y, Denzinger A, Schnitzler HU (2011) How greater mouse-eared bats deal with ambiguous echoic scenes. J Comp Physiol A 197 (in this issue). doi:10.1007/s00359-0100563-Z

Monroy JA, Carter ME, Miller K, Covey E (2011) Development of echolocation and communication vocalizations in the big brown bat, Eptesicus fuscus. J Comp Physiol A 197 (in this issue). doi: 10.1007/s00359-010-0614-5

Necknig V, Zahn A (2011) Between-species jamming avoidance in Pipistrelles? J Comp Physiol A 197 (in this issue). doi:10.1007/ s00359-010-0586-5

Neuweiler G (1970) Neurophysiologische Untersuchungen zum Echoortungssystem der Großen Hufeisennase Rhinolophus ferrumequinum Schreber. 1774. Z vergl Physiol 67:273-306

Neuweiler G (1989) Foraging ecology and audition in echolocating bats. Trends Ecol Evol 4:160-166

Neuweiler G (1990) Auditory adaptions for prey capture in echolocating bats. Physiol Rev 70:615-641

Neuweiler G (2000) The biology of bats. Oxford University, New York

Neuweiler G (2008) Und wir sind es doch—die Krone der Evolution. Wagenbach, Berlin

Neuweiler G, Möhres FP (1967) Role of spatial memory in orientation of Megaderma lyra. Z vergl Physiol 57:147-171

Neuweiler G, Schuller G, Schnitzler HU (1971) On-responses and off-responses in the inferior colliculus of the greater horseshoe bat to pure tones. Z vergl Physiol 74:57-63
Neuweiler G, Singh S, Sripathi K (1984) Audiograms of a south Indian bat community. J Comp Physiol A 154:133-142

Neuweiler G, Metzner W, Heilmann U, Rübsamen R, Eckrich M, Costa HH (1987) Foraging behavior and echolocation in the rufous horseshoe bat (Rhinolophus rouxi) of Sri Lanka. Behav Ecol Sociobiol 20:53-67

Odendaal LJ, Jacobs DS (2011) Morphological correlates of echolocation frequency in the endemic Cape horseshoe bat, Rhinolophus capensis (Chiroptera: Rhinolophidae). J Comp Physiol A 197 (in this issue). doi:10.1007/s00359-010-0601-x

Pollak GD (2011) Discriminating among complex signals: the roles of inhibition for creating response selectivities. J Comp Physiol A 197 (in this issue). doi:10.1007/s00359-010-0602-9

Ratcliffe JM, Jakobsen L, Kalko EKV, Surlykke A (2011) Frequency alternation and an offbeat rhythm indicate foraging behavior in the echolocating bat, Saccopteryx bilineata. J Comp Physiol A 197 (in this issue). doi:10.1007/s00359-011-0630-0

Sayegh R, Aubie B, Faure PA (2011) Duration tuning in the auditory midbrain of echolocating and non-echolocating vertebrates. J Comp Physiol A 197 (in this issue). doi:10.1007/s00359-0110627-8

Schmidt S, Yapa W, Grunwald JE (2011) Echolocation behaviour of Megaderma lyra during typical orientation situations and while hunting aerial prey: a field study. J Comp Physiol A 197 (in this issue). doi:10.1007/s00359-010-0552-2

Schmidtke D, Esser K-H (2011) Sex matters in echoacoustic orientation: gender differences in the use of acoustic landmarks in Phyllostomus discolor (lesser spear-nosed bat). J Comp Physiol A 197 (in this issue). doi:10.1007/s00359-010-0573-x

Schnitzler HU, Denzinger A (2011) Auditory fovea and Doppler shift compensation: adaptations for flutter detection in echolocating bats using CF-FM signals. J Comp Physiol A 197 (in this issue). doi:10.1007/s00359-010-0569-6

Schuller G, Neuweiler G, Schnitzler HU (1971) Collicular responses to the frequency modulated final part of echolocation sounds in Rhinolophus ferrumequinum. Z vergl Physiol 74:153-155

Simmons JA, Simmons AM (2011) Bats and frogs and animals in between: evidence for a common central timing mechanism to extract periodicity pitch. J Comp Physiol A 197 (in this issue). doi:10.1007/s00359-010-0607-4

Yovel Y, Franz MO, Stilz P, Schnitzler HU (2011a) Complex echo classification by echo-locating bats: a review. J Comp Physiol A 197 (in this issue). doi:10.1007/s00359-010-0584-7

Yovel Y, Geva-Sagiv M, Ulanovsky N (2011b) Click-based echolocation in bats: not so primitive after all. J Comp Physiol A 197 (in this issue). doi:10.1007/s00359-011-0639-4 